\title{
Exploring the link between management communication and emotions in mergers \& acquisitions
}

DOI:

10.1002/cjas. 1382

\section{Document Version}

Accepted author manuscript

Link to publication record in Manchester Research Explorer

\section{Citation for published version (APA):}

Zagelmeyer, S., Sinkovics, R. R., Sinkovics, N., \& Kusstatscher, V. (2018). Exploring the link between management communication and emotions in mergers \& acquisitions. Canadian Journal of Administrative Sciences, 35(1), 93-106. https://doi.org/10.1002/cjas.1382

\section{Published in:}

Canadian Journal of Administrative Sciences

\section{Citing this paper}

Please note that where the full-text provided on Manchester Research Explorer is the Author Accepted Manuscript or Proof version this may differ from the final Published version. If citing, it is advised that you check and use the publisher's definitive version.

\section{General rights}

Copyright and moral rights for the publications made accessible in the Research Explorer are retained by the authors and/or other copyright owners and it is a condition of accessing publications that users recognise and abide by the legal requirements associated with these rights.

\section{Takedown policy}

If you believe that this document breaches copyright please refer to the University of Manchester's Takedown Procedures [http://man.ac.uk/04Y6Bo] or contact uml.scholarlycommunications@manchester.ac.uk providing relevant details, so we can investigate your claim.

\section{OPEN ACCESS}




\title{
Exploring the link between management communication and emotions in mergers and acquisitions
}

\author{
Stefan Zagelmeyer • Rudolf R. Sinkovics • Noemi Sinkovics • Verena \\ Kusstatscher
}

\section{This is an Author's Original Manuscript (AAM) of an article published by Wiley in Canadian Journal of Administrative Sciences. Please cite the published article:}

Zagelmeyer, Stefan, Rudolf R. Sinkovics, Noemi Sinkovics, and Verena Kusstatscher (2016), "Exploring the link between management communication and emotions in mergers \& acquisitions," Canadian Journal of Administrative Sciences, Early view, in press. (DOI: 10.1002/cjas.1382). http://dx.doi.org/10.1002/cjas.1382

\section{Authors}

$\underline{\text { Stefan Zagelmeyer }}$

Reader in Comparative and International Business

The University of Manchester, Alliance Manchester Business School

Booth Street West, Manchester M15 6PB, UK.

(e-mail: Stefan.Zagelmeyer@manchester.ac.uk, www.manchester.ac.uk/research/s.zagelmeyer )

Rudolf R. Sinkovics $(\square)$

Professor of International Business

The University of Manchester, Alliance Manchester Business School

Booth Street West, Manchester M15 6PB, UK.

and Lappeenranta University of Technology, Lappeenranta, Finland

(e-mail: Rudolf.Sinkovics@manchester.ac.uk, www.manchester.ac.uk/research/rudolf.sinkovics )

Noemi Sinkovics

Lecturer in International Business

The University of Manchester, Alliance Manchester Business School

Booth Street West, Manchester M15 6PB, UK.

(e-mail: Noemi.Sinkovics@manchester.ac.uk, www.manchester.ac.uk/research/noemi.sinkovics )

Verena Kusstatscher

Varani Persönlichkeitsentwicklung, Team- und Organisationsentwicklung, Vienna, Austria 
Exploring the link between management communication and emotions in mergers and acquisitions

Stefan Zagelmeyer

The University of Manchester, Alliance Manchester Business School

Rudolf R. Sinkovics*

The University of Manchester, Alliance Manchester Business School and Lappeenranta

University of Technology

Noemi Sinkovics

The University of Manchester, Alliance Manchester Business School

Verena Kusstatscher

Varani Persönlichkeitsentwicklung, Team- und Organisationsentwicklung, Vienna

Acknowledgements: We gratefully acknowledge insightful comments received from Fang Lee Cooke, Monash University, Melbourne. We are also grateful to seminar participants at the Comparative and International Business Research Centre (CIBER) seminars at The University of Manchester, Alliance Manchester Business School.

* Please address correspondence to: Rudolf Sinkovics, The University of Manchester, Alliance Manchester Business School, Booth Street West, Manchester M15 6PB, United Kingdom.

Email: Rudolf.Sinkovics@manchester.ac.uk 


\section{Abstract}

News on merger and acquisition (M\&A) activities frequently dominate the popular business press. While the announcement of an M\&A usually elicits enthusiasm in the business community, it also results in increased levels of uncertainty, stress, and anxiety for employees. Based on a qualitative analysis of four international M\&A cases, this paper integrates emotions and communication during mergers and acquisitions in a conceptual framework. We argue that management communication and information flows during all stages of an M\&A process represent affective events, which in a cognitive appraisal process trigger positive and negative emotions. These in turn may influence employee attitudes, behaviour, and performance, and ultimately also M\&A success.

Keywords: communication, emotions, M\&As, international business

\section{Résumé}

Mots-clés: 
Mergers and acquisitions (M\&A) have been waxing and waning over the past decades. Buckley and Ghauri (2002) claimed that five merger waves characterized the world economic scene in the $20^{\text {th }}$ century that would be followed by two further waves before and after the financial crisis in 2008 (Weber, Teerikangas, Rouzies, \& Tarba, 2012). Yet, the public and management discourse reports poor performance of M\&As, despite a lack of conclusive empirical research evidence (Risberg \& Meglio, 2012).

As people-management issues are considered to be responsible for between one-third and one-half of all failures (Cartwright \& Cooper, 1993), the human side has become quite prominent in recent M\&A research (Angwin, Mellahi, Gomes, \& Peter, 2014; Schuler, Jackson, \& Luo, 2003; Stahl et al., 2013; Stahl \& Mendenhall, 2005; Weber \& Fried, 2011). While the role of management communication during M\&As is widely acknowledged (e.g., Allatta \& Singh, 2011; Angwin et al., 2014; Bastien, 1987; Davenport \& Barrow, 2009; Gomes, Angwin, Weber, \& Yedidia Tarba, 2013; Risberg, 1997; Soderberg, 2012; Weber, Tarba, \& Sandquist Öberg, 2014), the role of emotions has only recently been identified as a critical element in M\&A processes (Clarke \& Salleh, 2011; Gunkel, Schlaegel, Rossteutscher, \& Wolff, 2015; Kusstatscher \& Cooper, 2005; Sinkovics, Zagelmeyer, \& Kusstatscher, 2011).

Previous research on communication aspects is overwhelmingly directed towards the rational component of communication. The prevalent assumption is that communication has to be open, honest, and logical in order to convince employees, and ultimately to increase the levels of identification with and commitment to the new organization (e.g., Appelbaum, Lefrancois, Tonna, \& Shapiro, 2007; Davenport \& Barrow, 2009), thus largely ignoring the emotional component of communication. However, employees affected by M\&As regularly experience 
feelings of uncertainty and high levels of fear and anxiety mixed with anger, aggression, distrust, disappointment, frustration, and grief.

Despite the increasing recognition of emotions in management research (see e.g. Ashkanasy \& Daus, 2002; Elfenbein, 2007; Fineman, 2000), the empirical evidence on the antecedents, relevance, and the role of emotions in relation to employee attitudes, behaviour, and performance in M\&A processes is still rather patchy (see Clarke \& Salleh, 2011; Fugate, Kinicki, \& Scheck, 2002; Kiefer, 2002). This is especially true for the link between communication and emotions in M\&A processes. Drawing on qualitative work by and Sinkovics et al. (2011), Gunkel et al. (2015) used employee survey data in their multivariate analysis of the role of communication and emotions during an M\&A to show that employee emotions mediate management practices and employee behaviour—but did not find any significant relationship between managerial communication and employee's feelings. While the first attempt to engage in quantitative analysis on the topic is commendable, further and deeper analysis is needed, especially in terms of the complexity involved in M\&As processes, and where management communication and emotional aspects are concerned.

In order to encourage and inform future research on this topic, we seek to further elaborate the analytical aspects of earlier qualitative research (Kusstatscher \& Cooper, 2005; Sinkovics et al., 2011) by revisiting the existing qualitative dataset, by focusing explicitly on the between communication and emotions during different stages of merger and acquisition processes, and by suggesting avenues for future research on the link between communication and emotions in M\&As.

We next analyze the most recent literature on M\&As, communication, and emotions followed by our research objectives, methodology and data. We then present and discuss the 
empirical findings and then further specify an existing conceptual analytical framework, which can inform future quantitative research. The last section discusses the implications of our findings for future research and management practice.

\section{Emotions, Communication, and M\&As: The Conceptual Framework}

\section{M\&A Contingencies}

M\&As are complex phenomena, where individual cases are often reported to be idiosyncratic and unique. In order to identify and categorize emotional reactions of employees to management communication in M\&A processes, we distinguish (a) general M\&A deal characteristics and (b) the different stages of M\&As.

The first set of issues relates to the distinction between the acquiring and the acquired company, or in the case of mergers, between the dominant company and the company at the receiving end. Relatedly, one may distinguish between friendly or hostile takeovers (Martynova \& Renneboog, 2008). In a friendly acquisition, the target company that is receptive to takeover, provides access to information to facilitate due diligence, and both parties usually share the opportunity to structure the deal to their mutual satisfaction. In a hostile takeover the target has no desire to be acquired, actively rebuffs the acquirer, and refuses to provide any confidential information. The target may also use defensive tactics to avoid being taken over.

The second categorization concerns the type of M\&A: horizontal (business activities of the acquired company are related to those of the acquirer), vertical (organizations in a suppliercustomer relationship), conglomerate (related to a diversification strategy), or concentric (organizations from different but related industries) (Gomes, Brown, Weber, \& Tarba, 2011). 
More complex and varied is the third dimension, which concerns the motivations for the M\&A. Economic or business-related motivations include synergy effects or economies of scale and scope, which may lead to cost savings due to a better use of common resources and cost reductions. Further motivations relate to product diversification, tax optimization, access to technology, capital and/or markets (Gomes et al., 2011), achieving a dominant position in the industry, and being able to manipulate the rules of competition. Value creation for the acquirer (through either cost cutting or through added value due to increased scope) and financial problems or succession problems on the side of the selling company are further managerial reasons (Buono, Bowditch, \& Lewis, 2002; Jansen, 2001). On the other hand, there are psychological motivations such as fear of obsolescence, gaining (management) prestige through larger market shares, bored CEOs seeking excitement, the satisfaction of personal whims or empire-building (Cartwright \& Cooper, 1990, 2000; Napier, 1989). Related to motivations, Schuler et al. (2003) emphasized the political character, and draw our attention to the issue that various stakeholders (owners, society, organizational members, customers, suppliers, unions, alliance partners) may have—potentially conflicting_claims in the M\&A process.

Haspeslagh and Jemison (1991) and Ellis, Weber, Raveh, and Tarba (2012) distinguished different integration approaches, ranging from absorption to holding to symbiosis to preservation, each having distinct implications for employees. Related to this, one may distinguish different levels of integration. In full integration, all functional areas will be merged into one new company. Moderate integration involves the merging of certain key processes. Strategic decisions will be centralized within one entity, but day-to-day operating decisions will remain autonomous. Minimal integration means that only selected personnel will be merged. Both strategic and operating decisions will remain decentralized and autonomous. 
In the academic and consulting literature, M\&A processes are divided into several stages (for examples, see, e.g., Davenport \& Barrow, 2009; Weber et al., 2014). Our analysis follows Weber et al. (2014), who distinguished between a pre-merger planning and strategic management stage, a negotiation, due diligence, and agreement stage and a post-merger integrating the organizations stage.

While there are myriad M\&A characteristics, they are relevant in the context of the current paper as they first affect the risks, challenges and change requirements for and the impact of the M\&A on individual employees. Second, the complex structure of characteristics, motivations, and (potentially conflicting stakeholder) interests highlights the role of (strategic) management communication, which may vary across the different M\&A stages (Angwin et al., 2014; Davenport \& Barrow, 2009; Gomes et al., 2011; Weber et al., 2014). Both are expected to have an impact on the type and the extent of the emotional responses of employees.

\section{Communication}

It has long been recognized that communication plays an important role in M\&A processes. Communication distributes information about the extent and implications of organizational change, controls organizational member behaviour, fosters motivation and commitment, promotes a sense of belonging (Welch \& Jackson, 2007), and provides a release for emotional expression.

Communication has several dimensions. The content dimension includes the information that is being communicated. Communication may be formal — that is, managed by the organization —or informal — that is, emergent as a transmission of personal or social messages in the organization. It may be upward, downward, and/or lateral. While there may be different 
sources of information, the addressee may be a specific person, a group of employees or anonymous (Guirdham, 2002).

Communication processes may suffer from various deficiencies. The sender and/or receiver of information may deliberately or subconsciously use filters-that is, manipulate information when sending or taking in information—based on their interests, background, experience, and attitudes. The quantity of information may exceed human capacity, or emotions will influence how the message is interpreted. It is worth noting that words and concepts have different meanings to different people and that there can be dissonance between management communication and behaviour.

There is an extensive literature on communication in M\&A process, ranging from practitioner-oriented, prescriptive contributions (e.g., Appelbaum et al., 2007) to empirical research (Allatta \& Singh, 2011; Angwin et al., 2014; Bastien, 1987; Napier, Simmons, \& Stratton, 1989; Papadakis, 2005; Schweiger \& Denisi, 1991). Major challenges of M\&As for employees are the increased uncertainty and the ambiguity about the development of the organization, as well as the employee's future in the organization, which may be perceived as threatened (Amiot, Terry, \& Jimmieson, 2006). Employees seek information on the terms and conditions of the takeover deal and on the resulting implications for their employment (McClurg, 2002). Especially when management is reluctant or not able to deliver information, employees will turn to "communication to develop stable, socially derived interpretations of events and their meanings" (Lotz \& Donald, 2006, p. 3).

Research on the relationship between information adequacy and job satisfaction in acquisitions highlights that the design of communication needs to consider the nature of the information to be communicated, the goals of the organization, the specific needs and concerns 
of the employees, and the different needs and expectations of acquiring and acquired company employees (Ying, May, \& Rosenfeld, 2004). Risberg (1997) maintains that many of the ambiguities that employees face originate in unclear or nonexistent communication, or in the misinterpretation of communication. Van Dick, Ullrich, and Tissington (2006) found that genuine and clear communication, in contrast to manipulative communication, is a significant determinant of post-merger identification of employees, and thus M\&A success.

Communication positively influences perceptions of fairness as well as procedural and interactional justice (Lotz \& Donald, 2006), thus improving the acceptance of change. Klendauer and Deller (2009) found a significant relationship between interactional justice perceptions and affective commitment. Interactional justice perceptions relate to the employees' perception of being treated by managers during organizational processes, especially concerning (interpersonal and intraorganizational) communication between superiors and subordinates and the explanations of management decisions. Hubbard and Purcell (2001) emphasized the relevance of communication to manage employee expectations (and breaches thereof), which is ultimately associated with interpretations of the psychological contract.

Other authors inquire into the role of communication for management. Vaara and Monin (2010) emphasized the significance of communication for the discursive legitimization of an M\&A. Communication is used in strategic ways by management in order to yield particular behavioural responses on the side of the employees, and to support the process of postmerger culture integration as well as the development of a new corporate brand (Soderberg, 2012).

Angwin et al. (2014) emphasized the relevance of the process and content of communication during the different M\&A stages. Although the case study analysis shows great variations between communication approaches and M\&A performance, there is evidence that an 
immersive approach — that is, rich and continuous communication throughout the merger process—has a positive impact on employee commitment and organizational survival.

\section{Emotions}

While emotions have been studied extensively by various academic disciplines, there is still a lack of a consensual definition (Ashkanasy, Härtel, \& Zerbe, 2000; Elfenbein, 2007; Frijda, 2008; Guerrero, Andersen, \& Trost, 1996). In line with Frijda (2008), we understand emotion as a mental state of (action) readiness that arises from cognitive appraisals of events, social interactions, or thoughts. It has a phenomenological tone, but in contrast to other, relatively broad and open definitions, this definition presents emotion as a tangible phenomenon - that is, it implies action readiness (Frijda, 1986), which makes it easier to capture this mental state empirically. There are numerous classifications of emotions, ranging from anger, fear, joy, love, sadness to surprise, and there is an increasing literature on the impact of emotions on cognitions, attitudes, and behaviours in a work context (for oveviews, see Briner, 1999; Elfenbein, 2007; Weiss \& Cropanzano, 1996).There are various categorizations and classifications of emotions (Briner, 1999; Guerrero et al., 1996; Schwager \& Rothermund, 2013; Seo, Barrett, \& Bartunek, 2004). Several theoretical approaches seek to explain and analyze the emergence of emotions related to communication in an M\&A context. Cognitive appraisal theory (CAT) posits that the emergence of an emotion requires cognition in the form of appraisals (e.g., Frijda, 1986; Mandler, 1984; Schachter, 1964). Thus, emotions only appear as a response to a certain internal or external stimulus. Frijda (2008) argued that the processes underlying the phenomenon of emotions are linked to responses to information an individual person receives and processes. 
"Some of that information is received from the environment; some is generated by an individual's bodily processes; and some comes from the individual's store of representations of facts, cognitive schemas, and behavioral skills"(Frijda, 2008, p. 69).

In this sense, information related to M\&A processes, whether rumours among colleagues or the official announcement, can trigger such processes leading to emotional responses. Affective events theory (AET) provides a framework for exploring affective experiences such as moods and emotions in work settings. AET argues that certain situational aspects of the work environment, so-called affective events, systematically trigger human affect, which is the experience of positive (pleasant) and negative (unpleasant) emotions. The respective affective states would then lead to affect-driven behaviours and changes in work attitudes (Ashkanasy et al., 2000; Weiss \& Cropanzano, 1996).

Although emotions such as delight and enthusiasm, or anxiety, anger, fear, desperation, or grief can extend beyond the individual and be linked to a group, it is still the individual who experiences a certain emotion (see Lazarus, 1995). Yet we appreciate that emotions in individuals can be triggered by group-level processes or related to (social) identification with groups, as suggested by social identity theory (Hogg \& Terry, 2000; Ullrich, Wieseke, \& Dick, 2005). Social identity theory (SIT) helps to better understand the emotional dimension when two groups or identities (or organizations, in the case of M\&As) come in contact with each other and are supposed to be integrated. According to SIT, the extent of identification with the own ingroup will influence employee commitment, readiness to leave the culture, and willingness to adopt another identity (Ellemers, Spears, \& Doosje, 2002; Terry, Carey, \& Callan, 2001), which represents a highly emotional process. 
It is important to note that employees' emotions are not necessarily directly influenced by what managers actually do and say. According to the cognitive appraisal approach, employee emotions are shaped by their appraisal of communication (Frijda, 2008). However, what is more important is how these emotions are interpreted by employees and the meaning employees attribute to them. We therefore consider it important and reliable to focus on perceived managerial communication as an influencing factor of employees' emotions.

In the research literature, there is some awareness of the role of emotions in M\&A processes (e.g., Amiot et al., (2006); Clarke and Salleh (2011). In their cognitive-emotional model of organizational change Liu and Perrewé (2005) argue that appraisals during different stages of the change process trigger emotional responses, which affect the choice of coping behaviour and action tendencies. Kiefer (2005) showed that change processes trigger negative emotions, which lead to low levels of trust and withdrawal behaviour.

Sinkovics et al. (2011) explicitly analyzed and discussed the role of emotions in international M\&As, with a specific focus on the phenomenon of the merger syndrome. Drawing on elements from cognitive appraisal theory and affective events theory, they used qualitative indepth interviews with managers and employees and developed an analytical framework for investigating the role of emotions in M\&As (Figure 1). The framework includes employee outcome variables, which are influenced by three sets of independent (antecedent) variables, namely communication, management behaviour, and other M\&A-related contingencies. Emotions are considered an intermediary (mediator) variable between the antecedent variables and the outcome variables. The relationship between the antecedents, emotions, and outcome variables may be influenced by contextual (moderator) variables, which affect the strength of the respective relationships. For example, the direction and intensity of the individual employee's 
emotional response may depend on dispositional factors, belonging to a particular occupational group or simply on whether the individual is employed by the acquiring or the acquired company.

In their multivariate analysis of quantitative employee survey data, Gunkel et al. (2015) tested the model developed by Sinkovics et al. (2011). However, with respect to the link between communication and emotions, their analysis yielded no significant relationship between managerial communication and employee feelings of dissatisfaction and insecurity during an M\&A. We suspected that the lack of significant relationships may be a consequence of the specific items used to capture communication and exclusively negative emotions. We measured management communication through the employee survey questionnaire items "The takeover process is clear and understandable" and "Management and employees seem to possess the same information about the takeover." Feelings of dissatisfaction were measured through the items "I feel demotivated with the takeover because I am not involved in the change process,'” and "I feel abandoned and worthless during the change process." Feelings of insecurity were measured by the items "I experience much fear of economic loss, i.e. job loss," and "I experience a lot of stress, anxiety and uncertainty regarding the takeover"' (Gunkel et al., 2015).

We used the quantitative findings—or the lack thereof—by Gunkel et al. (2015) to further investigate the issues related to communication and emotions in merger and acquisition processes. The subsequent sections seeks to capture some of the complexity involved in M\&A processes by (i) looking at communication issues at different stages of the M\&A process and (ii) exploring a broader variety of (negative and positive) emotional responses to the M\&A event and related management communication. 


\section{Empirical Study}

\section{Research Method}

In view of the complexities and contingencies around communication and emotions, we devised a qualitative interview approach, and combined inductive methodology and deductive reasoning to explore the viability of our concepts in the framework. This follows EasterbySmith, Thorpe, and Lowe (2002), who argue that a qualitative approach permits flexibility and supports a fluid and continuous renegotiation of central dimensions of conceptual frameworks.

Our sampling process was driven by theoretical ambitions (Glaser \& Strauss, 1967). We attempted to identify organizations and individuals who were in possession of information necessary for developing and improving the analytical framework, and to this end, the population from which samples were drawn for this study was defined as companies with recent exposure to mergers and acquisitions. As the link between communication and emotions was expected to vary in relation to the different types of M\&As (partial or full), different establishments (of the acquiring or acquired company) and the occupational group (e.g., top-level management, middlemanagement, employees), we sought to obtain information from interviewees who populated these different categories. This process followed along the lines of the principle of purposive sampling as we proceeded with sampling at two levels: the organization and interviewee level. Organizations were chosen to represent particular M\&A types. Individuals were chosen according to their occupational group within the respective organizations. We stopped the sampling process when we felt that additional interviews would not contribute to additional insights regarding the link between communication and emotions in M\&As. 
Table 2

\section{Interviewee Characteristics and Interviewing Techniques Used}

We identified a total of fifteen interviewees after approaching company executives for support of the study. In addition, individuals within the company were approached on site, before and after scheduled interviews. Three of the interviewees were top managers/company owners, seven middle managers, and five employees held no management role. Four interviewees were female, eleven male. Eight of the interviewees reported that their career was affected by the changes due to the merger, one was dismissed, five did not experience major changes, and one case was outside these categories.

A semistructured interview guideline was developed to allow for largely open and freeflowing interviews with top managers, middle managers, and employees without supervisory function. This consisted of six sections and an introduction section where the purpose of the research was offered. Second, interviewees were asked to offer a historical account of the M\&A, and drawing on projective techniques and specifically critical incident technique, respondents were asked to capture turbulent and/or relatively tranquil periods in the process of cultural integration from a longitudinal perspective. This was facilitated by the request to think of their company as a person and to draw a "temperature curve." The third section of the interview guideline encompassed a conversation around the managerial communication of the M\&A (i.e. how the organizational change was "sold" internally, announced, and through which communication channels it was progressing). The next section encompassed specific incidents and management behaviour that triggered emotions, and the fifth section examined aspects of corporate culture and identity, job satisfaction and psychological factors. The interview guidelines concluded with aspects of personal relationships and perceived organizational 
performance. The interview protocol was piloted with two practitioners involved in M\&A and two academics knowledgeable in the subject area and subsequently revised before final deployment in the interviews. The interview narratives provided were augmented with observations (looking specifically at interviewee behaviour and cultural indicators) and secondary data (newsletter, newsletters) in order to obtain a comprehensive view of the changes within the organization. The interviews were recorded, transcribed, and systematically analyzed using computer-assisted qualitative data analysis software (CAQDAS) (Sinkovics, Penz, \& Ghauri, 2008)

The questions in the interview guideline were designed such that they did not constrain the flow of the interview and allowed for an open discussion about the company's pre- and postM\&A situation. The overarching ambition was to uncover managerial communication strategies and management activities in the M\&A process. To this end, the interview guidelines avoided referring to concepts such as emotions and feeling, both to facilitate an emotionally neutral interaction between interview partners and allow for new dimensions that previously did not exist in the research framework to emerge. The guideline also included sections on managerial communication, stress, management behaviour, emotions, culture and identity, and performance outcomes. Observations during the interviews were focused on reactions arising from questions asked and other sources of cultural indicators (e.g., architecture, dress codes, and specifically organizational mission statements).

\section{Trustworthiness of the Qualitative Analysis}

To enhance the trustworthiness of the qualitative analysis process, we used NVivo CAQDAS software and followed recommendations regarding qualitative analysis of primary interview data, as outlined by Sinkovics et al. (2008). As for qualitative research, the concepts of 
credibility, dependability, transferability, and confirmability were deemed more appropriate (Denzin \& Lincoln, 1994) and were adopted at various stages of the research process. In terms of credibility, we used existing literature to frame the research problem appropriately and adopted pre-established dimensions such as communication and emotions from salient M\&A literature bodies. Our theoretical sampling helped to ensure external credibility and throughout the data collection process we used multiple sources of evidence, without solely relying on interview transcripts and instead embedding observations and secondary pieces of information from websites and company reports in our NVivo text-database to establish a chain of evidence (Yin, 2003).

As for the dependability criterion of qualitative research, we used the interview guideline (protocol), outlined in the section on interviewing techniques. This ensured repeatability of our study and also provided a systematic structural approach for the development of a coding scheme from the data. Given different interview languages involved (German, English, Italian), we also carefully accounted for conceptual equivalence issues, as outlined by Sinkovics and Penz (2011). The major advantage in following these recommendations was that we arrived at a coding scheme that was consistent in terms of the meaning and interpretation of concepts across our cases and thus legitimized some form of transferability to other contexts. Finally, in terms of confirmability, for each of the interview transcripts we employed a secondary coder from the research team. The secondary coder was tasked with examining whether the categorization and interpretation of concepts was consistent across all cases and determining whether there were systematic reactions to the questions posed from the interview guideline. Differences in interpretation between the primary and secondary coder were discussed at length, interpretations 
were harmonized and codes were used consistently, allowing us to minimize issues of confirmability in this research.

\section{Findings}

\section{Stage I: Planning and Preparation Stage}

Interviewees unanimously acknowledged the relevance and importance of communication during the entire M\&A process. During the planning and preparation stages, only specific managers and employees may receive information on the planed M\&A. However, employees may suspect that M\&As are on the agenda as a consequence of published or communicated corporate strategy.

Employees who are not actively involved in M\&A-related decision making processes but are affected by these decisions expect detailed and regular updates from their superiors. If no such information is available, implicit and nonverbal cues are used to decode information.

"If you have a sense for feelings, you realize that something is seething there. Signals come from different sides. $(I-14, \S 39)$

"It was simply not foreseeable for employees. The upper elite, the upper management did of course know it, but the normal worker has no information. He only feels something. Thus, some rumors circulated."(I-11, § 223)

With regard to the planning and preparation stages, interviewees reported a feeling that "something is going on." The individual and subjective assessment of expected outcomes for the respective person will then determine whether or not the individual employee is responding emotionally, and in which direction (positive or negative). 


\section{Stage II: Negotiation, Due Diligence and Agreement Stage}

Despite top-level management's attempts to keep the processes secret, rumours may spread during the due diligence and negotiation processes (Marmenout, 2011). Irrespective of whether it was possible to keep information on the upcoming M\&A secret, the official announcement is an important and emotionally intensive (affective) event for all company members and can trigger diverse emotional responses.

'You wait trembling, 'what will this guy now tell us?' Partially we had read in the newspapers, but nothing concrete. And most of us clanged full of hope to the works meeting and to the general director's words." (I-6, § 33)

If employees were unaware of the upcoming changes, their reactions might demonstrate either shock or anxiousness (negative emotions) or delight, pride, or optimism (positive emotions), as in the quote above. The reaction depends on several factors: one aspect is how the information on the M\&A is delivered. Another issue is the reputation or perception of the partner company. Employees are understandably most concerned with foreseeable career changes or job losses. If, however, rumours have already circulated in advance of the official announcement, employees feel tense and insecure and long for an official explanation.

With respect to the analyzed cases, there was considerable variation concerning the announcement. Poma's willingness to discuss a M\&A with Leitner was given on the premise that the due-diligence process was undertaken in complete secrecy. Leitner's board members, who were informed personally by the owner about the M\&A, felt enthusiastic about the news and proud that their company was able to buy Poma, reflecting a positive emotional response of management in the acquiring company. 
In the case of Schwarzkopf, there were different interpretations of which event could be labelled "the announcement." For some, the announcement was the moment their department held an informal meeting in the office that Schwarzkopf was for sale and that there were several interested buyers. This moment was not considered emotionally very intensive. It prompted curiosity rather than anything else, and created a lot of speculation about potential buyers, which dominated the scene in the following days. When Henkel was known to be the potential buyer, people reacted differently: some felt this could be positive news and felt relatively happy.

"The funny thing was that we initially felt relatively happy about the fact that it was Henkel because we thought that nothing would change for us. Also company X considered buying us. And I recall that we said: 'Thank goodness, it is Henkel. This will be good for us.'” (I-6, $\S 18)$

Other employees described the increased emotional intensity as a "large amount of rage and anger" (I-6, § 50):

"The (emotional) intensity increased with the question 'who could buy us?' - and then: 'It is Henkel! This could be negative for us...' There was a large amount of rage and anger." $(I-6, \S 50)$

For others, this informal information was considered to be rumours. In their perception, the announcement was the official works meeting several weeks later when Henkel's CEO came to announce the news to all employees in the canteen of the Schwarzkopf subsidiary. Again, this official announcement was experienced in completely different ways: some were surprised, while others were delighted.

"It was a surprise, yes. And for some of us, me included, (it was) quite a delight: 'Finally something is going to happen here!' because the structures [of Schwarzkopf] were partly antiquated [...].” (I-8, §30) 
This emphasizes the variation in the extent and direction of emotional responses to a specific piece of information, depending on the personal and subjective appraisal of the situation.

Henkel's CEO proclaimed in a meeting in front of all Schwarzkopf employees: "Never change a winning team. You are successful and we are not going to change anything here [at this Schwarzkopf subsidiary]." Employees who knew prior to the announcement that their department would be closed and that their positions would therefore be made redundant felt shocked by the sense of hope communicated in the official announcement. Hence, they felt the communication was rather dubious. These employees felt angry and irritated by the official version of the news.

"I was also one of those who knew already that I would be dismissed. Therefrom emerges complete anger, of course. How can this guy stand up and raise the others' hope if there is no reason for hope?! This was for us lots of anger and somehow also a demotivation." (I-6, $\S 23-24)$

"A few asked questions, he answered professionally, but his answers were not tangible/ comprehensible. People certainly know it, but they don't want to accept it. There is an incredible bad atmosphere! To the point of shock, to the utmost anxiety, to the point of desperation... there were also people who were since a long time [in the company] and who had no chance to find another job." (I-7, § 132-133)

In this sense, there were ambiguous feelings and different emotional responses among the Schwarzkopf employees: on one hand there was hope amongst those who trusted the communicated message, and on the other, anxiety and desperation amongst those who had already received different information.

Sportler's owner informed his employees and those of the 10 Hervis outlets about the acquisition in two meetings: the "Meeting North" took place in one of the Sportler buildings and 
the "Meeting South" in the premises of an elegant hotel. The announcement itself was considered the "emotionally most intensive event" of the M\&A; afterwards the intensity declined quickly. During the meeting, the Sportler management team presented its goals and programs, and tried to provide reassurance to the former Hervis staff by announcing that no one would be dismissed. They also tried to generate support for the M\&A among the workforce. Some Hervis' members felt very enthusiastic about the upcoming and much anticipated changes and expressed their happiness immediately; others were somewhat reserved, which again reflects emotional responses in different directions.

"Of course, some employees jumped enthusiastically up, embraced us already at the end of the presentation and said: 'great that you are here!' 'finally!' and 'excellent!' And there were of course others who were more reserved." (I-9, § 51)

Sportler also announced that they would contact each outlet in the near future and they presented the respective new contact persons, which was described as a highly emotional moment.

The acquisition of Staff by Zumtobel and the merger between Zumtobel Staff and Thorn were announced through a letter/email and through the so called "chairman's letter" with a photo of the owner and his signature. Top-managers had learned about the M\&A plans in an earlier meeting. In both cases rumours could not be avoided. Sales people, for example heard the news from clients.

The four case studies showed that announcements vary, and that individuals experience the same announcement in different ways. Interviewees recommended that the announcement and the information process should be based on clear and honest decisions followed by a wellprepared official announcement to all employees in order to reduce uncertainty and avoid 
rumours. It was also suggested that this communication should be done by the top-management or by the company owner. Once the initial information on the M\&A is available, it is crucial to ensure employees do not feel uncertainty for any length of time. Those (negatively) affected should be well-informed. Announcement and messages should be transmitted through several "channels" in parallel and by arranging small group conversations rather than one large event. In contrast to suggestions to have the announcement in a big company meeting with room for questions (e.g., Appelbaum, Gandell, Shapiro, Belisle, \& Hoeven, 2000; Cartwright \& Cooper, 2000), the interviews reveal that in such meetings employees are often overwhelmed by their feelings of excitement or shock, and that they don't dare to ask particularly daunting questions.

\section{Stage III: Post-Merger Integration Stage}

Our research also provides evidence for the link between the managerial communication style (openness, honesty, and frequency) and employees' positive/negative emotions during the postmerger integration stage.

"The communication came in with delay and was incomplete. (...) They only received fragments. Thus, the feelings of uncertainty intensified.” (I-7, § 43)

"Information is the motivation factor above all." (I-3, § 102)

The not-knowing generates uncertainty and demotivation: Interviewees reported that the level of information provided by superiors in organizations would vary depending on the position held by the employee and his or her personal contact with the superiors.

A lack of information is considered suspicious. Several interview partners, irrespective of being associated with the acquiring or the acquired company, reported that they were not sure about how much their superiors knew about the M\&A. In cases where employees had the feeling 
that their superiors had more information than what was, communicated, employees became suspicious and began to distrust their managers, thus reporting negative emotions.

"In the beginning we were comprehensively informed (...) and then there were periods in which you did not hear anything anymore. And if you hear nothing at all, it starts to be very suspicious.” (I-12, § 32)

From a managerial perspective there are several reasons for not communicating all known information. First, managers often do not have the complete information and do not want to concern employees if unnecessary. Second, the informed person either feels stressed and has "no time" to communicate or s/he does not consider the information warrants communication to employees. Third, management may be strategically hiding information and avoiding open communication.

Interestingly, all interviewees in management positions (with only two exceptions) reported not having been sufficiently informed by their superior(s), which is a clear reference to low communication satisfaction. On the other hand, they were convinced they were sufficiently and frequently communicating with their subordinates.

The interviews also revealed varying opinions of what is deemed "enough" information and "frequent" communication. Because perceptions create realities, perceptions of the recipients of information are important.

It appears that in such delicate situations, people thoroughly absorb in high detail communications from managers regardless of whether it is positive or negative. These pieces of information will be recalled even after long periods of time. For example, three interview partners from the acquired company independently mentioned that a certain manager from the buying company said in front of the members of the acquired company: "Lots of blood and water 
will flow". Those words triggered significant anxiety, resistance, and rumours among employees at the time. Recalling those words still elicit anger among the interviewees after six years.

On the other hand, there are also examples of intensive positive emotions caused by managerial communication.

"Mister [X from the buying company] who accompanied the merger (...) walked around the factories and approached colleagues, often at seven o'clock in the morning, to ask about their sorrows and problems. The employees loved him, although many were dismissed nevertheless. Even today, people are still asking how this guy is doing.” (I-12, § 104)

Lack of official top-down information leads to rumours among employees. Such rumours often correlate with feelings of uncertainty and other unpleasant emotions such as fear, anger, frustration, demotivation, or hopelessness. Sixteen statements in the interviews confirm the link between poor managerial communication, perceptions of uncertainty, and the spreading of rumours, which lead to demotivation and to lower productivity. Interviewee statements further confirm that open and honest information is the most effective way to reduce rumours.

"Incredible, what ideas and rumors turned up! This is quite obvious. In a period of uncertainty someone drops something and this develops a momentum of its own.” (I-8, § 74)

"Such news goes of course very fast around the company. It spreads like a wildfire. Lots of negative energy grew out of this. And people talked a lot about it instead of working productively.” (I-12, § 32)

"Rumors are around anyway. But the better you inform, of course, and the more security you give the less I have to make up in order to reduce my anxieties. In most of the time it is the suppression or the ignoring of fears that leads to fantasizing. There were of course people who stirred these rumors up. No doubt. (They) disseminated even more uncertainties. But unconsciously. Driven by their own anxieties, perhaps.” (I-8, § 74-75) 
In addition to internal communication, it is important to consider information from external sources. For example, newspaper articles, which are not always privy to balanced information, strongly influence employees' emotions. They are a source of rumours and emotions like irritation, anxiety and fear, aggression, rage, jealousy, de-motivation, grief, or arrogance. Employees expect a managerial reaction and explanation when worrisome media releases appear. Public media releases do not only affect employees; bad news can scare and irritate employees' families, potential job applicants, and clients.

"Then we read those stories in the newspaper. They sounded very bad. They talked about mass dismissals and bank disasters. At that time we would have appreciated to hear something from the management floor about what really was going on. This caused a feeling of considerable uncertainty amongst the colleagues. You were thinking 'how are things about my job?' Lots of anxieties raised out of these articles." (I-12, § 32)

\section{Discussion}

In contrast to the quantitative analysis by Gunkel et al. (2015), our empirical findings provide evidence for a link between communication and emotions in M\&A processes. Consistent with the propositions of cognitive appraisal theory, affective events theory, and social identity theory, M\&A-related communication triggers a large variety of positive and/or negative emotional responses during all stages of the M\&A process, depending on contingencies such as the characteristics of the M\&A, the type and content of communication and available information, and the subjective appraisal of the situation by the employee. 
From the empirical analysis, a conceptual framework emerges that goes beyond Sinkovics et al. (2011). Figure 2 presents the conceptual model of the role of communication and emotions in M\&A processes. For employees, an M\&A as such along with the related managerial activities, including management communication, constitutes one or a series of affective events that trigger emotional responses.

\section{Figure 2}

There are several ways in which M\&A events can influence employee attitudes, behaviour, and performance, some of which are mediated by emotional responses of the employees, with or without further mediation of management communication. The different options can be summarized in a $2 \times 2$ matrix, involving (i) the incidence of management communication (yes/no) and (ii) whether or not the information (either directly from the M\&A event or indirectly mediated through management communication) is associated with emotional loading (i.e., —an emotional response on the side of the employee [yes/no]).

The direction of the emotional response (in line with the approach outlined in Figure 1) is determined by a subjective cognitive appraisal of the receiver of the communication (e.g., in terms of negative or positive consequences for the individual employee). The magnitude of the response is determined by the affect intensity of the event (i.e., the degree to which the event is subjectively perceived as intense, as well as the emotional regulation capacity of the individual). Rational cognitive processes and emotional response will then have an impact on employee attitudes, behaviour, and performance, which will ultimately influence M\&A success.

Figure 2 represents a simplification of complex processes and contingencies. As described above, there are different M\&A motivations, objectives, integration approaches, and process stages to be considered in more elaborate analysis. In terms of complexity, the same holds true 
for communication and emotions. Context variables (e.g., acquired vs. acquiring company, hostile vs. friendly takeover) and case-specific employee variables (e.g., potential winner/loser as result of M\&A, emotional maturity, occupational and employment group) act as moderating variables.

Going beyond mere exploration of the phenomenon, there are several fertile avenues for future research. In general terms, quantitative research, similar to Gunkel et al. (2015), could use these insights to develop more adequate and valid measures of M\&A characteristics, communication styles, and content as well as the emotional responses of employees. More specifically, it would be useful to inquire into and analyze the relative importance of the M\&A event (factual dimension) itself, the information available on the M\&A (information content dimension), and the type of communication (communicative dimension) on employee emotions. The respective results could be used by management to derive appropriate information and communication policies.

\section{Conclusion}

The traditional management literature mostly assumes that organizations are rather logical and rational entities, and oftentimes ignores that highly emotional events such as M\&As interfere with logic and rationalism. Our research extends research by Sinkovics et al. (2011) by focusing on the link between communication and emotions, the stages of the M\&A process, and different M\&A characteristics. Consistent with the propositions of cognitive appraisal theory, affective events theory, and social identity theory, M\&A-related communication triggers a large variety of positive and/or negative emotional responses during all stages of the M\&A process, 
depending on contingencies such as the characteristics of the M\&A, the type and content of communication and available information, and the subjective appraisal of the situation by the employee. The conceptual framework developed in this paper on the role of communication and emotions in M\&A processes can be used to derive propositions and hypotheses to inform future quantitative research along the lines of and extending the most recent research by Gunkel et al. (2015).

This paper calls for an increasing awareness for emotions during M\&As and emphasizes the role of managerial communication as affective events, which trigger emotional responses. In terms of practical implications, managers need to develop awareness for people and their emotions. Those who ignore their responsibility to manage emotions will be faced with employee withdrawal behaviour from disappointed, unsatisfied, uncommitted, and demotivated employees. This may lead to lower levels of productivity, and/or increases in absenteeism and turnover. Beyond the level of awareness, the knowledge that communication triggers emotional reactions of their causes and consequences allows management to design communication policies for M\&A processes better.

Positive M\&A related emotions facilitate the M\&A integration. A well-managed and positively experienced merger can also prevent unhealthy relationships among co-workers and cure deteriorating relationships between employees and superiors. Employees who are wellinformed about organizational changes tend to more easily and more quickly identify themselves with the new organization and demonstrate higher commitment towards the new organization. What constitutes "sufficient" information and "frequent" communication is only a subjective and individual perception. 
Interviews established a distinct connection between managerial communication style (openness, honesty, and frequency) and employees' positive/negative emotions. In periods of major change such as a postmerger situations, employees need frequent and regular information. Informed knowledge about what is going on has positive effects upon employees' feelings. Without news, uncertainty is rampant and staff is hugely unforgiving regarding prolonged periods of uncertainty.

The creation of internal and external information and communication processes allows for consistently and openly informing employees within appropriate timeframes about changes. Literature confirms that this creates transparency and thus a sense of integrity and trustworthiness (Goleman, Boyatzis, \& McKee, 2002; Marks \& Mirvis, 1992)

Most M\&As necessarily involve unpleasant decisions. However, our research findings revealed that employees' reaction mainly depends on how bad news is communicated and how individuals are treated by the management. Purely "logical" and "rational" communication of the motives to merge is not always sufficiently convincing for employees. Avoidance or attempts to reduce the intensity of emotions does not help. Management needs to accept that emotions play a critical role in M\&As. Given that measures of organizational performance are the result of people involving themselves collectively in the pursuit of organizational goals, the management of emotions is imperative for M\&A's success. 


\section{JEL Classification: M10, M12, M16}

\section{References}

Allatta, J. T., \& Singh, H. (2011). Evolving communication patterns in response to an acquisition event. Strategic Management Journal, 32(10), 1099-1118. doi: 10.1002/smj.930

Amiot, C. E., Terry, D. J., \& Jimmieson, N. L. (2006). A longitudinal investigation of coping processes during a merger: Implications for job satisfaction and organizational identification. Journal of Management, 32(4), 552-574. doi: 10.1177/0149206306287542

Angwin, D. N., Mellahi, K., Gomes, E., \& Peter, E. (2014). How communication approaches impact mergers and acquisitions outcomes. The International Journal of Human Resource Management, 1-28. doi: 10.1080/09585192.2014.985330

Appelbaum, S. H., Gandell, J., Shapiro, B., Belisle, P., \& Hoeven, E. (2000). Anatomy of a merger: Behavior of organizational factors and processes throughout the pre- duringpost-stages (part 2). Management Decision, 38(10), 674-684. doi: $10.1108 / 00251740010360579$

Appelbaum, S. H., Lefrancois, F., Tonna, R., \& Shapiro, B. T. (2007). Mergers 101 (part one): Training managers for communications and leadership challenges. Industrial \& Commercial Training, 39(3), 128-136. doi: 10.1108/00197850710742225

Ashkanasy, N. M., \& Daus, C. S. (2002). Emotion in the workplace: The new challenge for managers. The Academy of Management Executive, 16(1), 76-86. doi: 10.5465/AME.2002.6640191

Ashkanasy, N. M., Härtel, C. E. J., \& Zerbe, W. J. (2000). Emotions in the workplace: Research, theory, and practice. In N. M. Ashkanasy, C. E. J. Härtel \& W. J. Zerbe (Eds.), Emotions in the workplace: Research, theory, and practice (pp. 1-35). Westport: Quorum Books 
Bastien, D. T. (1987). Common patterns of behavior and communication in corporate mergers and acquisitions. Human Resource Management Review, 26(1), 17-33. doi: 10.1002/hrm.3930260103

Briner, R. B. (1999). The neglect and importance of emotion at work. European Journal of Work and Organizational Psychology, 8(3), 323-346. doi: 10.1080/135943299398212

Buckley, P. J., \& Ghauri, P. N. (Eds.). (2002). International mergers \& acquisitions. London: International Thomson Business Press.

Buono, A. F., Bowditch, J. L., \& Lewis, J. W., III. (2002). When cultures collide: The anatomy of a merger. In P. J. Buckley \& P. N. Ghauri (Eds.), International mergers \& acquisitions (pp. 307-324). London: International Thomson Business Press

Cartwright, S., \& Cooper, C. L. (1990). The impact of mergers and acquisitions on people at work: Existing research and issues. British Journal of Management, 1, 65-76.

Cartwright, S., \& Cooper, C. L. (1993). The psychological impact of merger and acquisition on the individual: A study of building society managers. Human Relations, 46(3), 327-347. doi: $10.1177 / 001872679304600302$

Cartwright, S., \& Cooper, C. L. (2000). HR know-how in mergers and acquisitions. London: Institute of Personnel and Development.

Clarke, N., \& Salleh, N. M. (2011). Emotions and their management during a merger in brunei. Human Resource Development International, 14(3), 291-304. doi: $10.1080 / 13678868.2011 .585064$

Davenport, J., \& Barrow, S. (2009). Employee communication during mergers and acquisitions. Farnham [u.a.]. 
Denzin, N. K., \& Lincoln, Y. S. (Eds.). (1994). Handbook of qualitative research. Thousand Oaks: Sage Publications.

Easterby-Smith, M., Thorpe, R., \& Lowe, A. (2002). Management research: An introduction (2nd ed.). London: Sage Publications.

Elfenbein, H. A. (2007). Chapter 7: Emotion in organizations -- a review and theoretical integration. The Academy of Management Annals, 1, 315 - 386.

Ellemers, N., Spears, R., \& Doosje, B. (2002). Self and social identity. Annual Review of Psychology, 53, 161-186. doi: 10.1146/annurev.psych.53.100901.135228

Ellis, K. M., Weber, Y., Raveh, A., \& Tarba, S. Y. (2012). Integration in large, related M\&As: Linkages between contextual factors, integration approaches and process dimensions. European Journal of International Management, 6(4), 368-394. doi: 10.1504/ejim.2012.048154

Fineman, S. (Ed.). (2000). Emotion in organizations (2nd ed.). London: Sage Publications.

Frijda, N. H. (1986). The emotions. Cambridge: Cambridge University Press.

Frijda, N. H. (2008). The psychologist's point of view. In M. Lewis, J. M. Haviland-Jones \& L. F. Barrett (Eds.), Handbook of emotions (3 ed., pp. 68-87). New York: The Guilford Press

Fugate, M., Kinicki, A. J., \& Scheck, C. L. (2002). Coping with an organizational merger over four stages. Personnel Psychology, 55(4), 905-928. doi: 10.1111/j.17446570.2002.tb00134.x

Glaser, B. G., \& Strauss, A. L. (1967). The discovery of grounded theory: Strategies for qualitative research. Chicago: Aldine Pub. Co. 
Goleman, D., Boyatzis, R. E., \& McKee, A. (2002). The new leaders: Transforming the art of leadership into the science of results. London: Little Brown.

Gomes, E., Angwin, D. N., Weber, Y., \& Yedidia Tarba, S. (2013). Critical success factors through the mergers and acquisitions process: Revealing pre- and post-M\&A connections for improved performance. Thunderbird International Business Review, 55(1), 13-35. doi: $10.1002 /$ tie. 21521

Gomes, E., Brown, C., Weber, Y., \& Tarba, S. Y. (2011). Mergers, acquisitions and strategic alliances understanding the process. Houndmills, Basingstoke, U.K.: Palgrave MacMillan.

Guerrero, L. K., Andersen, P. A., \& Trost, M. R. (1996). Chapter 1 - communication and emotion: Basic concepts and approaches. In P. A. Andersen \& L. K. Guerrero (Eds.), Handbook of communication and emotion (pp. 3-27). San Diego: Academic Press. doi:10.1016/B978-012057770-5/50003-5

Guirdham, M. (2002). Interactive behaviour at work (3rd ed.). London: Financial Times Prentice Hall.

Gunkel, M., Schlaegel, C., Rossteutscher, T., \& Wolff, B. (2015). The human aspect of crossborder acquisition outcomes: The role of management practices, employee emotions, and national culture. International Business Review, 24(3), 394-408. doi: 10.1016/j.ibusrev.2014.09.001

Haspeslagh, P. C., \& Jemison, D. B. (1991). Managing acquisitions: Creating value through corporate renewal. New York: Free Press. 
Hogg, M. A., \& Terry, D. J. (2000). Social identity and self-categorization processes in organizational contexts. Academy of Management Review, 25(1), 121-140. doi: 10.5465/AMR.2000.2791606

Hubbard, N., \& Purcell, J. (2001). Managing employee expectations during acquisitions. Human Resource Management Journal, 11(2), 17-33. doi: 10.1111/j.1748-8583.2001.tb00036.x Jansen, S. A. (2001). Mergers \& acquisitions: Unternehmensakquisitionen und -kooperationen (4th ed.). Wiesbaden: Gabler.

Kiefer, T. (2002). Understanding the emotional experience of organizational change: Evidence from a merger. Advances in Developing Human Resources, 4(1), 39-61. doi: $10.1177 / 1523422302004001004$

Kiefer, T. (2005). Feeling bad: Antecedents and consequences of negative emotions in ongoing change. Journal of Organizational Behavior, 26(8), 875-897. doi: 10.1002/job.339

Klendauer, R., \& Deller, J. (2009). Organizational justice and managerial commitment in corporate mergers. Journal of Managerial Psychology, 24(1), 29-45. doi: $10.1108 / 02683940910922528$

Kusstatscher, V., \& Cooper, C. (2005). Managing emotions in mergers and acquisitions. Cheltenham, U.K.: Edward Elgar Publishing Ltd.

Lazarus, R. S. (1995). Emotions express a social relationship, but it is an individual mind that creates them. Psychological Inquiry, 6(3), 253-265. doi: 10.1207/s15327965pli0603_14

Liu, Y., \& Perrewé, P. L. (2005). Another look at the role of emotion in the organizational change: A process model. Human Resource Management Review, 15(4), 263-280. doi: 10.1016/j.hrmr.2005.12.001 
Lotz, T., \& Donald, F. (2006). Stress and communication across job levels after an acquisition. South African Journal of Business Management, 37(1), 1-8.

Mandler, G. (1984). Mind and body: Psychology of emotion and stress. New York: Norton.

Marks, M. L., \& Mirvis, P. H. (1992). Rebuilding after the merger: Dealing with 'survivor sickness'. Organizational Dynamics, 21(2), 18-32. doi: 10.1016/0090-2616(92)90061-Q

Marmenout, K. (2011). Peer interaction in mergers: Evidence of collective rumination. Human Resource Management, 50(6), 783-808. doi: 10.1002/hrm.20458

Martynova, M., \& Renneboog, L. (2008). A century of corporate takeovers: What have we learned and where do we stand? Journal of Banking \& Finance, 32(10), 2148-2177. doi: 10.1016/j.jbankfin.2007.12.038

McClurg, R. F. (2002). Human resources concerns. In D. J. BenDaniel, A. H. Rosenbloom \& J. J. Hanks (Eds.), International $m \&$ a, joint ventures, \& beyond (2 ed., pp. 485-505). New York: Wiley

Napier, N. K. (1989). Mergers and acquisitions, human resource issues and outcomes: A review and suggested typology. Journal of Management Studies, 26(3), 271-287. doi: 10.1111/j.1467-6486.1989.tb00728.x

Napier, N. K., Simmons, G., \& Stratton, K. (1989). Communication during a merger: Experience of two banks. Human Resource Planning, 12(2), 105-122.

Papadakis, V. M. (2005). The role of broader context and the communication program in merger and acquisition implementation success. Management Decision, 43(2), 236-255. doi: $10.1108 / 00251740510581948$ 
Risberg, A. (1997). Ambiguity and communication in cross-cultural acquisitions: Towards a conceptual framework. Leadership \& Organization Development Journal, 18(5), 257266. doi: $10.1108 / 01437739710182403$

Risberg, A., \& Meglio, O. (2012). Mergers and acquisitions outcomes - is it meaningful to talk about high failure rates? In Y. Weber (Ed.), Handbook of research on mergers and acquisitions (pp. 147-171). Cheltenham: Edward Elgar

Schachter, S. (1964). Interaction of cognitive and physiological determinants of emotional states. In L. Berkovitz (Ed.), Advances in experimental social psychology (Vol. 1, pp. 49-80). New York: Academic Press

Schuler, R., Jackson, S., \& Luo, Y. (2003). Managing human resources in cross-border alliances. London: Routledge.

Schwager, S., \& Rothermund, K. (2013). Counter-regulation triggered by emotions: Positive/negative affective states elicit opposite valence biases in affective processing. Cognition \& Emotion, 27(5), 839-855. doi: 10.1080/02699931.2012.750599

Schweiger, D. M., \& Denisi, A. S. (1991). Communication with employees following a merger: A longitudinal field experiment. Academy of Management Journal, 34(1), 110-135. doi: $10.2307 / 256304$

Seo, M.-G., Barrett, L. F., \& Bartunek, J. M. (2004). The role of affective experience in work motivation. Academy of Management Review, 29(3), 423-439. doi: 10.5465/AMR.2004.13670972

Sinkovics, R. R., \& Penz, E. (2011). Multilingual elite-interviews and software-based analysis. International Journal of Market Research, 53(5), 705-724. doi: 10.2501/IJMR-53-5-705724 
Sinkovics, R. R., Penz, E., \& Ghauri, P. N. (2008). Enhancing the trustworthiness of qualitative research in international business. Management International Review, 48(6), 689-714. doi: $10.1007 / \mathrm{s} 11575-008-0103-\mathrm{Z}$

Sinkovics, R. R., Zagelmeyer, S., \& Kusstatscher, V. (2011). Between merger and syndrome: The intermediary role of emotions in four cross-border M\&As. International Business Review, 20(1), 27-47. doi: 10.1016/j.ibusrev.2010.05.002

Soderberg, A.-M. (2012). Facilitating mergers through management and organization of communication: An analysis of strategic communication in a cross-border merger. In Y. Weber (Ed.), Handbook of research on mergers and acquisitions (pp. 233-258). Cheltenham: Edward Elgar

Stahl, G. K., Angwin, D. N., Very, P., Gomes, E., Weber, Y., Tarba, S. Y., . . Y Yildiz, H. E. (2013). Sociocultural integration in mergers and acquisitions: Unresolved paradoxes and directions for future research. Thunderbird International Business Review, 55(4), 333356. doi: $10.1002 /$ tie. 21549

Stahl, G. K., \& Mendenhall, M. E. (Eds.). (2005). Mergers and acquisitions: Managing culture and human resources. Stanford, CA: Stanford Business Books.

Terry, D. J., Carey, C. J., \& Callan, V. J. (2001). Employee adjustment to an organizational merger: An intergroup perspective. Personality and Social Psychological Bulletin, 27(3), 267-280. doi: 10.1177/0146167201273001

Ullrich, J., Wieseke, J., \& Dick, R. V. (2005). Continuity and change in mergers and acquisitions: A social identity case study of a German industrial merger. Journal of Management Studies, 42(8), 1549-1569. doi: 10.1111/j.1467-6486.2005.00556.x 
Vaara, E., \& Monin, P. (2010). A recursive perspective on discursive legitimation and organizational action in mergers and acquisitions. Organization Science, 21(1), 3-22. doi: $10.1287 /$ orsc. 1080.0394

Van Dick, R., Ullrich, J., \& Tissington, P. A. (2006). Working under a black cloud: How to sustain organizational identification after a merger. British Journal of Management, 17(S1), S69-S79. doi: 10.1111/j.1467-8551.2006.00479.x

Weber, Y., \& Fried, Y. (2011). Guest editors' note: The role of HR practices in managing culture clash during the postmerger integration process. Human Resource Management, 50(5), 565-570. doi: 10.1002/hrm.20449

Weber, Y., Tarba, S. Y., \& Sandquist Öberg, C. (2014). A comprehensive guide to mergers \& acquisitions. Upper Saddle River, NJ.

Weber, Y., Teerikangas, S., Rouzies, A., \& Tarba, S. Y. (2012). Mergers and acquisitions management: New directions. Editorial. European Journal of International Management, 6(4), 363-367.

Weiss, H. M., \& Cropanzano, R. (1996). Affective events theory: A theoretical discussion of the structure, causes and consequences of affective experiences at work. In B. M. Staw \& L. L. Cummings (Eds.), Research in organizational behavior: An annual series of analytical essays and critical reviews (Vol. 18, pp. 1-74). Greenwich, CT: JAI Press

Welch, M., \& Jackson, P. R. (2007). Rethinking internal communication: A stakeholder approach. Corporate Communications: An International Journal, 12(2), 177-198. doi: $10.1108 / 13563280710744847$

Yin, R. K. (2003). Case study research: Design and methods. Thousand Oaks, Ca.: Sage Publications. 
Ying, Z., May, S. K., \& Rosenfeld, L. B. (2004). Information adequacy and job satisfaction during merger and acquisition. Management Communication Quarterly, 18(2), 241-270. doi: $10.1177 / 0893318904267722$ 
Table 1: Companies Involved in the Study

\begin{tabular}{|c|c|}
\hline Company & Company background and $M \& A$ context \\
\hline Leitner & $\begin{array}{l}\text { - Leitner (Italy) was a producer of lifts, cableways, urban transport } \\
\text { systems, snow groomers and snowmaking systems. } \\
\text { - In } 2000 \text { Leitner bought the second biggest competitor on the global } \\
\text { market, Poma (France) to become world-market leaders in their sector. } \\
\text { - Interviews were conducted with Leitner members. }\end{array}$ \\
\hline Schwarzkopf & $\begin{array}{l}\text { - Schwarzkopf (Germany) was a producer of hair care products. } \\
\text { - In } 1995 \text { all Schwarzkopf subsidiaries were sold to Henkel (Germany). } \\
\text { - Within the first two years after the takeover, Henkel closed most of the } \\
\text { Schwarzkopf subsidiaries and transferred the production of selected } \\
\text { Schwarzkopf products to Henkel subsidiaries. } \\
\text { - Interviews were conducted with former Schwarzkopf staff from the } \\
\text { Austrian based subsidiary Kematen (next to Innsbruck). }\end{array}$ \\
\hline Sportler & $\begin{array}{l}\text { - Sportler is a South Tyrolian family owned sport retail company. } \\
\text { - In } 1999 \text { Sportler decided to buy } 10 \text { Italian outlets of the sport article } \\
\text { wholesaler Hervis (Austria). }\end{array}$ \\
\hline Staff & $\begin{array}{l}\text { - Medium sized German producer of light systems, sold to the Austrian } \\
\text { family business Zumtobel after the demise of the family owner. } \\
\text { - In } 2000 \text { Zumtobel merged with one of its biggest competitors, the UK } \\
\text { based light system producer Thorn. } \\
\text { - Interviews were conducted with both, former Staff and Zumtobel } \\
\text { members. }\end{array}$ \\
\hline
\end{tabular}


Figure 1. The role of emotions in M\&As

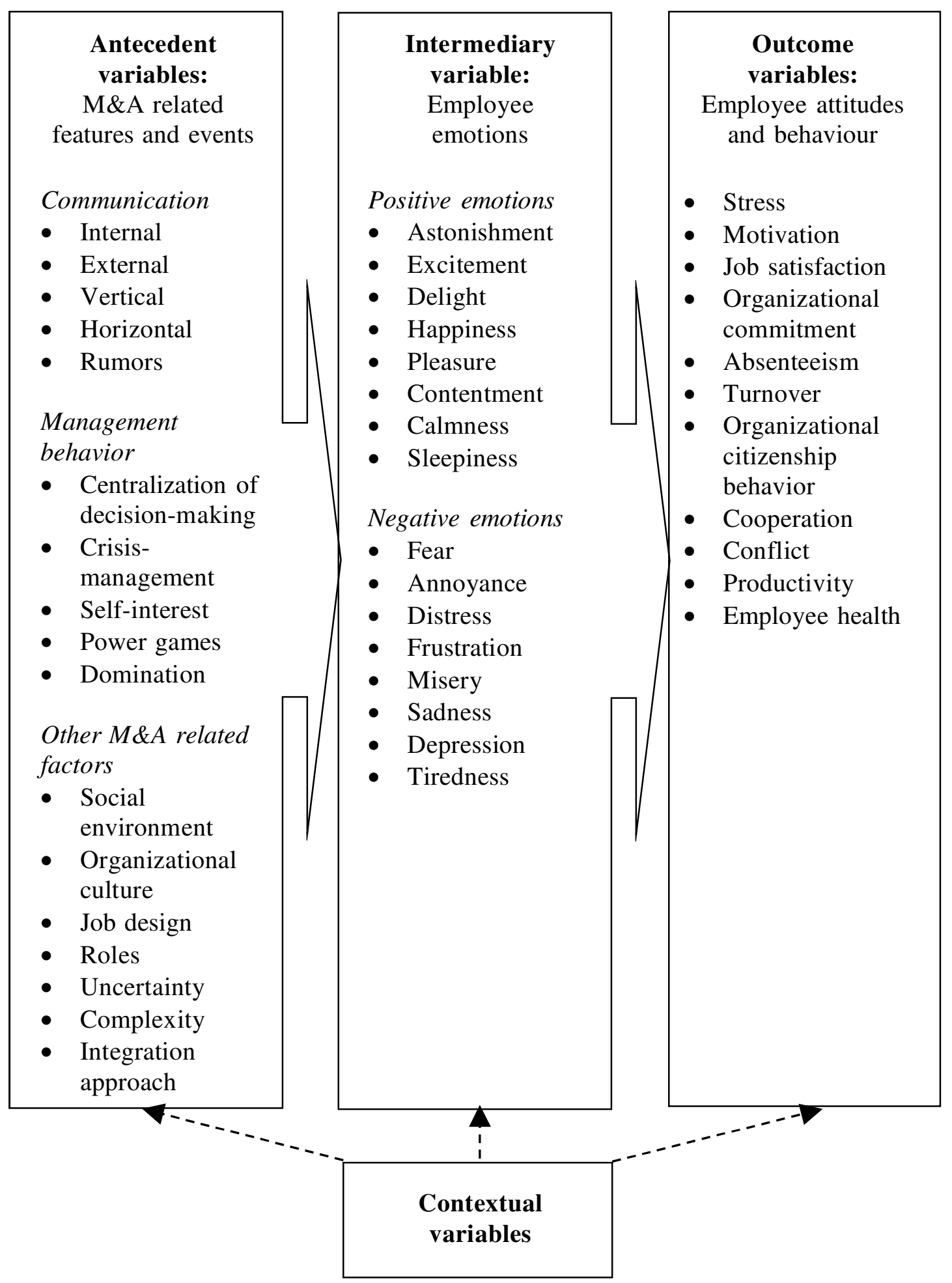

Source: Adapted from Sinkovics et al. (2011) and Gunkel et al. (2015), integrating the distinction between positive and negative emotions by Guerrero et al. (1996). 
Figure 2. Communication and emotions in the context of mergers and acquisitions

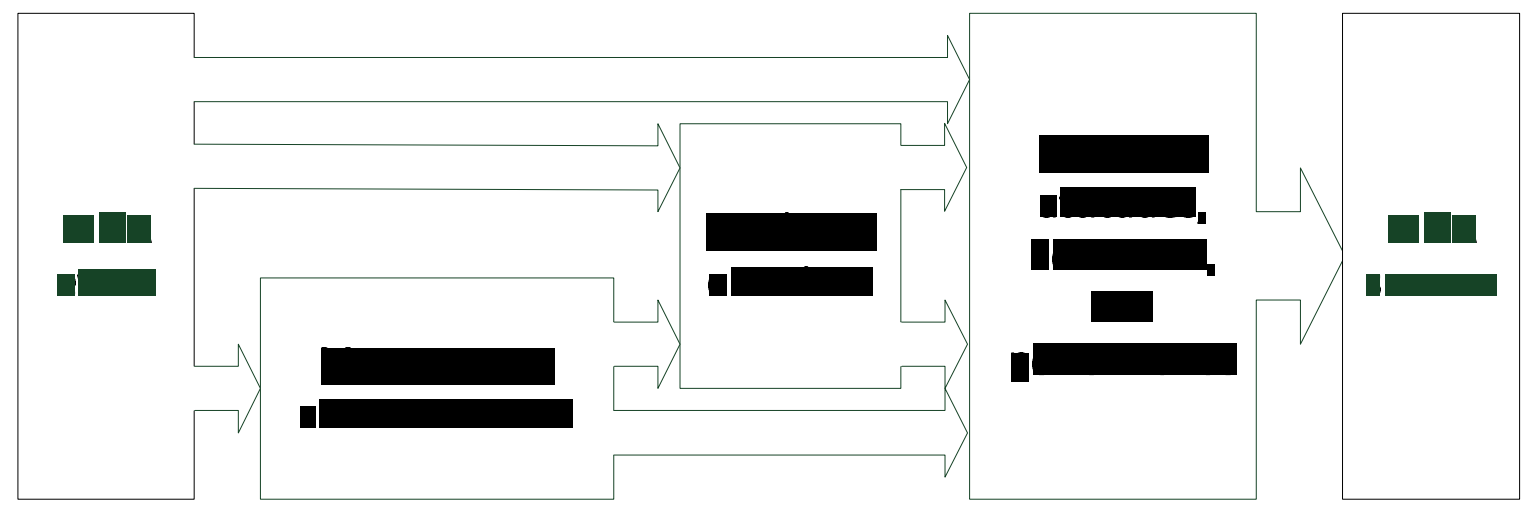

